Brit. F. vener. Dis. (1972) 48, 1

Presidential Address to the M.S.S.V.D. Systemic disease and the biological false positive reaction

\author{
R. D. CATTERALL \\ fames Pringle House, The Middlesex Hospital, London
}

During the past decade, one of the most rapid and important developments in medicine has been in immunology, and the greatest progress has been made in the isolation, characterization, and demonstration of antibodies. As a result of these advances insight has been gained into those immune reactions which may cause tissue destruction. The ability of the human immune system to distinguish between 'self' and 'not self' is important not only as a defence against invading micro-organisms, but also in distinguishing transformed host cells that may have become malignant.

An immune response is not always beneficial to the host. It can cause serum sickness with urticarial rashes, albuminuria, arteritis, and synovitis, anaphylactic reactions, and the well-known difficulties in organ grafting. It is now becoming apparent that both humoural antibody production and cell-mediated immunity may be involved in the pathogenesis of immune injury. If the immune system is defective, the mechanisms that prevent immunocytes and antibodies from reacting with normal components of the body may break down and cause autoimmune disease, and the ability of certain autoantibodies to cause functional or structural damage is no longer disputed. Methods of selectively altering these harmful reactions are needed, and considerable progress is already being made in understanding them. The aetiology of most immunopathological lesions is, however, still unknown, and it is not usually possible to imitate human disease completely in animals and with experimental models. The situation is also frequently complicated by external or genetically determined alterations in responses to common antigens and the science of immunology has a long way to go before it can fully explain many human diseases.

\title{
Serological tests for syphilis
}

In venereology the long and close collaboration between clinicians and serologists has resulted in a detailed understanding of many immunological aspects of syphilis. Much of modern immunology

began when Bordet (1898) described haemolysis, and soon afterwards Bordet and Gengou (1901) described the phenomenon of complement fixation. Employing these two discoveries. Wassermann, Neisser, and Bruck (1906) introduced the Wassermann reaction (WR), the first satisfactory serological test for the diagnosis of human disease.

Wassermann used as the antigen a saline extract from the livers of foetuses with congenital syphilis, thinking that treponemal material was responsible for the apparent specificity of the test. It was soon demonstrated that the test was non-specific in the usual immunological sense, when Marie and Levaditi (1907) prepared a successful antigen from the livers of non-syphilitic, new-born babies. Michaelis (1907) showed that flocculation techniques could be used to demonstrate syphilitic antibodies in the serum, but the method did not become popular until it was reintroduced by Meinicke (1917).

The fact that saline or better still alcoholic extracts of normal tissue provide satisfactory antigens for the Wassermann reaction is a paradox that has not been completely resolved. Since 1906 a large number of antigens have been studied and more than 200 different antigens are now known. Each country has tended to use its own modification of the tests, but gradually the cardiolipin Wassermann reaction and the Kolmer test have emerged as the most popular complementfixation procedures. The most commonly used flocculation tests are the Kahn, Price, Eagle, Hinton, Kline, and Venereal Disease Research Laboratory (VDRL) tests. The complement-fixation and flocculation tests have together become known as the standard serological tests for syphilis (STS). All are based on the same immunological and physico-chemical processes and differ from one another only in certain technical details. The antigens were formerly prepared by extracting ox heart muscle with ethanol and adding cholesterol as a sensitizing agent, but Pangborn (1941) extracted an acid phospholipid, cardiolipin, which appears to be the active antigenic component of the extracts. This pure chemical substance is now widely used as the antigen, together with carefully adjusted proportions of lecithin and cholesterol, and it will fix 
complement or flocculate with syphilitic serum. Substances similar to cardiolipin are found not only in heart muscle and other tissues but also in wheat germ and bacterial cells.

The antibody detected by these non-specific lipoidal antigens, syphilitic reagin, should not be confused with other types of reagin, which occur in atopic disease and belong to the IgE class of immunoglobulins. Syphilitic reagin is non-specific, is not directed solely against Treponema pallidum, and occurs with equal frequency in the other treponemal diseases, such as yaws, bejel, and pinta.

The questions why and how reagin forms in patients with syphilis and other diseases has frequently been discussed, but a satisfactory answer is not yet available. Similar antibodies occur in some patients with non-syphilitic disease and in the sera of some healthy animals. Furthermore, injection of lipoidal antigen into animals does not lead to reagin production, unless the antigen is mixed with a carrier protein. Even as early as 1907, Weil and Braun considered reagin to be an autoantibody produced by tissue breakdown. Sachs, Klopstock, and Weil (1925) suggested that tissue lipids set free during tissue destruction might react with treponemal protein and lead to the production of antibody reactive with lipoidal antigens, but Eagle and Fleishman (1948) thought that reagin might be produced by $T$. pallidum itself and that its reactivity with lipoidal antigens might be due to the treponemes having lipoidal antigens similar to those in normal tissues.

It may be asked why reagins occur predominantly in patients with treponemal infection, although widespread tissue damage occurs in a great number of other diseases. Kahn, Marcus, McDermott, and Adler (1942) showed that every serum contains traces of reagin, but that the quantities are so minute that specially sensitive tests are necessary to demonstrate it. Kahn (1951) went on to suggest that serological reactivity in syphilis was part of a universal reaction caused by antilipoidal antibody resulting from various lipids liberated by normal tissue destruction in health and by tissue damage in disease. Because reagin reacts with human tissue antigens, it is usually thought of as an autoantibody, but there is no evidence that it can cause tissue damage per se. It has been suggested that this is because the lipids are usually intracellular and thus prevented from uniting with antibody.

Reagin begins to appear in the serum 1 to 2 weeks after the development of the primary chancre and tests for its detection usually reach their maximum titre during the secondary stage of the disease. During the latent phase the reagin diminishes to the point that in about a quarter of untreated cases it may be no longer detectable, but in most cases it persists for the rest of the patient's life. Recent studies have shown that both IgM and IgG globulins are increased in early syphilis and that IgA may be raised in the secondary stage (Laurell, Oxelius, and Rorsman, 1968; Delhanty and Catterall, 1969). In late syphilis IgG predominates, but there may be high levels of IgM in some late cases of the disease (Aho, 1968).

In treated cases there is usually a rapid decline in titre in primary and secondary syphilis and the tests for reagin usually become negative after 4 to 8 months. In late syphilis of all types, the usual effect of treatment is to reduce the titre of tests for reagin; a proportion of these cases become seronegative, but the majority remain positive.

The fact that some persons who have not been infected by treponemal disease have reagins in their serum in such quantities that the standard serological tests are positive, has been a subject of investigation for many years. Such reactions were often called nonsyphilitic or non-specific, but gradually the term 'biological false positive reaction' came to be used to distinguish them from false positive reactions due to technical variation or error. In areas of the world where the incidence of syphilis is low, biological false positive reactions become relatively more common and more important. In general, the more sensitive the test the more liable it is to give false positive reactions, and since the standard serological tests have become the screening tests for treponemal disease their sensitivity has been increased, with a corresponding increase in non-specific reactions.

Ever since serological tests were first used attempts have been made to use $T$. pallidum as the antigen. Turner (1939) showed that serum from syphilitic animals and man contains a specific antibody, which combines directly with $T$. pallidum, so that its ability to infect rabbits is diminished or lost. Nelson (1948), working in Turner's laboratory, attempting without success to grow $T$. pallidum on artificial media, made a major advance when he developed a medium in which the organism could survive and remain motile for several days. Nelson and Mayer (1949) then prepared a suspension of motile treponemes in this medium together with syphilitic serum and complement and incubated the mixture under strictly anaerobic conditions at $35^{\circ} \mathrm{C}$. for 18 hours. The treponemes were immobilized and killed, whereas with normal serum they remained actively motile. These observations formed the basis of the treponemal immobilization test (TPI), which was the first practical, specific test for treponemal infections.

Absorption experiments have shown that immobi- 
lizing antibody is distinct from reagin and the other antibodies detected by other tests. It does not occur in the serum of normal persons or of those suffering from non-treponemal diseases, but occurs uniformly in cases of syphilis and the other related treponematoses. It does not occur in other spirochaetal diseases such as leptospirosis, relapsing fever, rat-bite fever, or Vincent's infection.

In untreated syphilis immobilizing antibody usually becomes detectable late in the primary stage. It is almost invariably present during the secondary stage and is always present in the latent stage, when it is detectable at the highest titres. It is almost always present in cases of late symptomatic syphilis, except in some very long-standing cases, such as quiescent tabes dorsalis or congenital syphilis of the late middleaged or elderly. This latter fact can be a source of diagnostic error if the results of the TPI test are viewed in isolation.

Treatment seems to have little effect on the presence of immobilizing antibody, and except in early infections of short duration it tends to persist for the remainder of the patient's life. However, Atwood, Miller, Stout, and Norins (1968) have recently produced some evidence that immobilizing antibody may disappear from the serum after treatment in about 10 per cent. of cases of latent and late symptomatic syphilis.

In order to explain the persistence of immobilizing antibody after adequate treatment, it was suggested by Collart, Borel, and Durel (1964) that T. pallidum must remain concealed somewhere in the tissues of the host. Detailed studies by Collart and others (1964), Yobs, Clark, Mothershed, Bullard, and Artley (1968), and other investigators, have demonstrated the presence of treponeme-like structures in the lymph nodes, cerebrospinal fluid, and aqueous humour of patients treated for latent and late syphilis. In a small number of cases it has been shown that the organisms are living and potentially virulent $T$. pallida, but in the majority infectivity tests have been inconclusive.

At the present time, it seems reasonable to conclude that strict bacteriological and 'immunological' cure of syphilis is achieved for certain only if treatment is given within the first 2 years of infection. Thereafter, despite adequate treatment, antibodies may well remain detectable in the patient's serum for the rest of his life, and the antigens responsible for these antibodies are probably related to the spiral organisms persisting in tissues and body fluids. It is not known whether these spiral organisms can again become pathogenic to the host or infectious to others.

Because of the expense and technical difficulties of the TPI procedure and the requirement that the test sera should be free of treponemicidal agents, many attempts have been made to develop tests lacking these disadvantages but equally specific. Inability to grow $T$. pallidum in vitro remains the major obstacle to the development of entirely satisfactory, highly specific tests. The use of the cultivable Reiter treponeme (probably not a strain of $T$. pallidum, but more likely related to $T$. refringens) as a source of protein antigen in the Reiter protein complement-fixation test (RPCFT), at first appeared to be promising, but later extensive experience has shown that a significant proportion of false positive reactions occurred. For this reason the RPCFT is now used with tests for reagin as a screening procedure of superior specificity.

When fluorescent antibody tests were developed it was inevitable that they should be applied to the serodiagnosis of syphilis. In the original procedure devised by Deacon, Falcone, and Harris (1957) the test serum at a dilution of 1 in 5 , was applied to $T$. pallida on a slide, and these coupling with human antibody in turn coupled with anti-human globulin conjugated with fluorescein isocyanate; fluorescence of treponemes was then visualized microscopically under ultra-violet light. The low dilution of serum and the later use of fluorescein isothiocyanate resulted in an oversensitive procedure giving false positive results due to detection of a group reactive antitreponemal antibody shared by T. pallidum and many other treponemes and spirochaetes, including the common commensals in the mouth and genitalia. Deacon, Freeman, and Harris (1960) described the FTA-200 test, in which the sera were diluted to 1 in 200 , which permitted the detection of specific antibody for $T$. pallidum, but was thought to be above the usual threshold for group antitreponemal antibody. As a result the FTA-200 test was insensitive though highly specific.

Further work led to the development of the absorbed fluorescent treponemal antibody (FTA-ABS) test by Hunter, Deacon, and Mayer (1964). In this test the group reactive antibody is absorbed out from the test serum with a concentrated filtrate of the culture medium on which Reiter treponemes have been grown (sorbent). The group reactive antibody can also be absorbed out with intact or ultrasonically disintegrated Reiter treponemes, but these are less satisfactory than sorbent.

The FTA-ABS test has been extensively investigated (Deacon, Lucas, and Price, 1966; Hunter, Norins, Falcone, and Stout, 1968). In untreated primary syphilis it is the most sensitive test available and becomes positive before the STS. At all stages of syphilis, it is reactive more frequently than the STS or the TPI test, and after treatment it appears to be- 
have in a similar manner to the TPI test. In patients treated early in the disease reversal to negative may occur but more slowly than with other tests, and when treatment is started late in the disease this test remains positive, frequently for the rest of the patient's life.

The specificity of the FTA-ABS test has been debated by many authors. There may be reactivity with sera containing abnormal globulins (Mackey, Price, Knox, and Scotti, 1969), antinuclear factor (Jokinen, Lassus, and Linder, 1969), and rheumatoid factor (Wilkinson and Rayner, 1966). More recently Kraus, Haserick, and Lantz (1970) have reported on the beaded appearance of the fluorescence of treponemes with sera from patients with lupus erythematosus, which does not occur with syphilitic sera. There appears to be no doubt that false positive reactions may occur, and Wilkinson and Ferguson (1968) have shown that sorbent may not remove all the group antitreponemal antibody present in strongly reactive sera. Furthermore, Király, Jobbágy, and Kováts (1967) have demonstrated that absorption of sera with Reiter treponemes does not always remove group reactivity against all treponemes, and it is probable that more than one group antitreponemal antibody may be present in the serum.

The advantages of the FTA-ABS test are very great. It is a very sensitive test, it employs a specific antigen, the technique is relatively simple, and it is suitable for testing large numbers of sera. However, there is still some doubt about its specificity with some sera, and, in the diagnosis of the biological false positive reaction, it has not yet displaced the TPI test as the final serological arbiter in doubtful cases. More work is needed on the basic principles of this test and further experience of its use in the diagnosis of the $\mathrm{BFP}$ reaction is required.

A satisfactory screening procedure for treponemal disease is to perform the WR and quantitative VDRL tests, using cardiolipin as antigen, and the RPCFT. In cases in which the diagnosis is not apparent on clinical and serological grounds, the FTA-ABS should be used. In cases of doubt or uncertainty the TPI test will be necessary. To establish the diagnosis of the chronic biological false positive reaction beyond reasonable doubt, a negative result with the TPI test must be obtained on two separate specimens of serum examined several months apart. If this is not done errors of diagnosis may occur in a small number of cases.

\section{Biological false positive reactions}

Although clinicians had long suspected that false positive reactions occurred in a proportion of patients with positive results to STS, little accurate informa- tion was available until the second world war. In 1938 a programme of mass blood testing was started in the United States, and during the second world war over $16,000,000$ young people had blood tests performed on entry into the U.S. armed services. Many were carefully investigated during outbreaks of infectious diseases such as the acute exanthemata, malaria, infective hepatitis, and infectious mononucleosis in conditions that would not have been possible in peace time. Presumed biological false positive reactions were found to be much more frequent than had been believed in the past. Furthermore, during the massive demobilization of the United States Forces at the end of the War, over 80,000 persons, who were known to be seronegative on entering the services and had no record of venereal disease or antisyphilitic treatment, were found to be seropositive on discharge. Further investigations indicated that about 40,000 probably did not have syphilis and were BFP reactors (Moore and Mohr, 1952).

In their large private practice in a prosperous city in the east of the United States, Moore and Mohr (1952) reported that about half of their patients found to have positive serological tests for syphilis did not, in fact, have syphilis, but gave the BFP reaction. Before the introduction of the TPI test in 1949, it was only possible to guess, on the results of a careful history, physical examination, and epidemiological investigation of the family and sexual contacts, whether the patient was a BFP reactor or not. However, the TPI test was soon shown to be highly specific for syphilis and endemic treponematoses (Zellman, 1954; Miller, Brody, and Hill, 1957) and, if carefully performed, to be highly reproducible (Sequeira and Wilkinson, 1955). As a result of detailed evaluation of the TPI test, it was shown that it could be used to distinguish accurately between treponemal disease and the BFP reaction.

Moore and Mohr (1952) introduced the concept of acute and chronic BFP reactions. The acute reaction occurs during or shortly after any of a variety of acute, infectious, non-syphilitic diseases and disappears within a few days, weeks, or months-never longer than 6 months-after the acute illness has subsided. Some common conditions resulting in the acute reaction are infectious mononucleosis, infective hepatitis, measles, chicken-pox, upper respiratory infections, virus pneumonia, and recent vaccination or inoculation. There are many other precipitating causes and it is probable that almost any condition which results in fever may produce an acute false positive reaction in a suitable individual.

Chronic BFP reactions occur in the absence of any of the causes of acute reactions and may last for years or frequently for the rest of life. The only infectious 
disease known to be associated with chronic reactions is leprosy, but this does not account for many cases and treponemal disease is common amongst patients with leprosy (Scotti, Mackey, and Trautman, 1970). The chronic BFP reaction is usually defined as the occurrence of repeatedly positive results to STS over a period of many months or years, in a patient with no historical or clinical evidence of syphilis or other treponemal diseases, normal results to tests of the cerebrospinal fluid, a normal chest $X$ ray, and screening of the aorta, and two negative TPI test results on two different specimens of sera taken several months apart. In addition, epidemiological investigations of the family and sex partners should be negative. Moore and Lutz (1955) claimed that, using these criteria, the margin of error in diagnosis could be reduced to about 2 per cent. However, Tuffanelli, Wuepper, Bradford, and Wood (1967) have drawn attention to the possibility of errors in diagnosis due to the relative insensitivity of the TPI test in late syphilis. They stated that the tests necessary to establish the presence of a chronic BFP reaction must include the FTA test as well as the TPI test, and they described a series of patients originally diagnosed as BFP reactors who, on more careful study, were shown to have syphilis.

Moore and Lutz (1955) reported their findings in 148 chronic BFP reactors followed up for a period of 6 years. They showed that there was a high incidence of autoimmune diseases in the group, ten patients having proven systemic lupus erythematosus (SLE) and 45 possible connective tissue disease. Shulman and Harvey (1964) continued the study of Moore's original patients and added many new ones to the series. They confirmed that SLE and less frequently discoid lupus erythematosus, Sjögren's disease, scleroderma, autoimmune haemolytic anaemia, purpura, and sometimes rheumatoid arthritis developed in a significant proportion of their patients, often after some years of observation. The same authors also reported Hashimoto's thyroiditis in false positive reactors. More recently Tuffanelli (1968a) found a high incidence of BFP reactions in drug addicts.

The chronic BFP reaction is much commoner in women than in men, and in Shulman and Harvey's series women outnumbered men by 3 to 1 . The reaction is frequently detected for the first time in women between the ages of 20 and 35 years. However, no age group is exempt, and Tuffanelli (1966) and Carr, Becker, and Carpenter (1966) found a number of chronic BFP reactors in patients over 60 years of age. The chronic reaction may occur many years before the onset of a collagen disease. and Haserick and Long (1952) reported five cases in which the positive STS preceded the onset of SLE by up to 8 years.
There is evidence that a genetic factor may be involved in the development of the chronic BFP reaction. Harvey and Shulman (1966) reported eleven patients with one or more close relatives with the BFP reaction and Tuffanelli (1968b) found a higher incidence of raised serum gamma globulin levels, antinuclear factors, and rheumatoid factors in 199 relatives of 103 chronic BFP reactors than in a series of control patients.

Other abnormalities are frequently found in the sera of patients with chronic BFP reactions. There may be raised serum globulin levels, anaemia, a raised erythrocyte sedimentation rate (ESR), abnormal liver function tests, abnormal immunoglobulins, antinuclear, rheumatoid, and LE-cell factors. In a few there may be a high level of circulating anticoagulant (Harvey and Shulman, 1966). Thyroid antibody is often present in appreciable amounts.

The antibodies associated with chronic BFP reactions are usually IgM in type, but they may also be of IgG type or a combination of the two (Tringali, Julian, and Herbert, 1969; Delhanty and Catterall, 1969). Anticomplementary activity in complementfixation tests occurs not only in the presence of raised gamma globulins but also when the serum contains antigen-antibody complexes such as cryoglobulins and rheumatoid factors (Lassus, 1969). Anticomplementary results in screening tests for syphilis may, therefore, provide a clue to an underlying disorder which requires investigation.

False positive reactions with lipoidal antigens are usually of low titre, although rarely they occur at high titre. Tringali, del Carpio, and Giammanco (1966) found that the titres were abolished by treatment of the sera with mercaptoethanol, whereas they were not affected in syphilis. Unfortunately, it has been subsequently shown that there are too many exceptions in both groups to make this a reliable diagnostic test (Delhanty and Catterall, 1969).

The antibodies responsible for the BFP reaction cross the placenta into the foetal circulation during pregnancy. There is some evidence that those antibodies detected by the complement-fixation tests cross the placenta more readily than those responsible for flocculation reactions. These passively transferred antibodies disappear from the infant's serum within a few weeks. IgM antibodies are believed not to cross the placental barrier and the presence of IgM type of antitreponemal antibody in the serum of an infant is believed to indicate that the infant is responding to an infection. If the FTA-ABS test employing a specific anti-IgM conjugate is positive on the infant's serum, it is reasonable to suspect that the child is infected with syphilis and that the antibody is not due to passive transfer of antibody from the mother (Scotti and 
Logan, 1968; Alford, Polt, Cassady, Straumfjord, and Remington, 1969). Biological false positive reactions are believed to be very uncommon in tests on the cerebrospinal fluid.

\section{The present series}

All the patients described in the present series have been seen personally during the past 16 years. They have come from a variety of sources. There were 74 patients with acute biological false positive reactions, 54 of whom were attending clinics for venereal diseases and were found to have positive STS at routine blood testing. Twelve were referred from antenatal clinics, six came from the blood transfusion services, and two were referred by other physicians (Table I).

TABLE I Sources of 74 acute biological false positive reactors

\begin{tabular}{ll}
\hline Source & No. of cases \\
\cline { 1 - 2 } Clinics for venereal diseases & 54 \\
Antenatal clinics & 12 \\
Blood transfusion services & 6 \\
Other physicians and surgeons & 2 \\
\hline Total & 74 \\
\hline
\end{tabular}

A diagnosis of the acute BFP reaction was made only if the STS were positive on three or more occasions on different specimens of serum, and there were negative results to the TPI test and more recently to the FTA test. There was no history suggestive of syphilis or other treponemal disease and detailed physical examination did not reveal any signs suggestive of those diseases. The positive STS disappeared spontaneously within weeks or monthsalways less than 6 months-and in the majority of cases the patients were followed for a further 6 to 12 months, and the STS remained negative throughout this period.

The acute BFP reaction could be shown to have occurred in association with a variety of events in fifty cases. It followed recent vaccination against smallpox in eleven patients and recent inoculation with $T A B$ vaccine in five. Infective hepatitis was present in five and infectious mononucleosis in three. Virus pneumonia had occurred in three, chicken-pox and measles in two each, and virus encephalitis in one. The only unusual event in eighteen young women was pregnancy; in all of these patients the STS became negative either later in the pregnancy or after delivery and remained negative for 6 months or longer during the postnatal period. In all cases the babies were clinically normal and seronegative at 6 weeks and 3 months of age.
TA B LE I I Presumed causes of 74 acute biological false positive reactions

\begin{tabular}{lrl}
\hline Cause & No. of cases \\
\cline { 1 - 1 } Recent vaccination against smallpox & 11 \\
Recent inoculation with TAB vaccine & 5 \\
Infective hepatitis & 5 \\
Infectious mononucleosis & 3 \\
Virus pneumonia & 3 \\
Chicken-pox & 2 \\
Measles & 2 \\
Virus encephalitis & 1 \\
Pregnancy only & 24 \\
Undetermined & 74 \\
\hline Total & 7 \\
\hline
\end{tabular}

The cause of the acute BFP reaction remained undetermined in 24 cases. There was no history of a possible precipitating factor and no abnormality on clinical examination, and the serological tests became seronegative within 6 months and remained negative throughout the follow-up period.

Moore and Mohr (1952) estimated that about 20 per cent. of the population were potential acute BFP reactors under appropriate circumstances. This small series confirms that recent vaccination against smallpox is one of the commonest precipitating factors. Although many cases are detected during pregnancy, there is no certain evidence that pregnancy itself is the cause of the acute reaction, although this could well be the case. In a substantial proportion of cases it was impossible to determine the cause of the reaction despite extensive investigations and willing cooperation from the patients. There are probably a large number of potential precipitating factors and there is no evidence from this or other series that the acute reaction has any serious significance for the patient other than the risk of misdiagnosis.

The situation with the patients diagnosed as having chronic BFP reactions was quite different. In this series the chronic BFP reaction was diagnosed only in those patients whose sera produced positive results to STS in repeated tests for a minimum period of one year, but in whom there was no past history of syphilitic infection, no clinical evidence of syphilis on careful physical examination, a negative result to the TPI test and, in the more recent cases, a negative FTAABS test result, as well as negative tests of the cerebrospinal fluid and a normal chest $X$ ray. In an attempt to reduce the margin of error in diagnosis to a minimum, two TPI tests and two FTA-ABS tests on different specimens of serum were carried out wherever possible.

Detailed questions were asked about the patients' medical and family histories. Whenever possible the families were examined and their blood tested. Over 
the years the majority have been examined repeatedly and investigations have included haematological studies, estimation of the ESR, total plasma proteins, and plasma albumin and globulin, study of the electrophoretic pattern of the plasma proteins, liver function tests, estimation of the serum cholesterol and examination of the peripheral blood for LE-cells, all performed at suitable intervals. More recently tests for autoantibodies, antinuclear factors, rheumatoid factors, and immunoglobulin levels have been carried out on the sera of all the patients. Other pathological and radiological investigations were performed when appropriate. The period of follow-up has varied from 1 to 12 years.

The patients came from all social classes and their homes were widely scattered throughout the United Kingdom, but were predominantly in the London area and Yorkshire. Altogether there were $130 \mathrm{chronic}$ biological false positive reactors ( 94 women and 36 men). Of the 94 women, there were 91 white, two of negro origin, and one Indian. Of the 36 men, there were 33 of European origin, one Indian, one Chinese, and one Negro. The ages ranged from 17 to 74 years, but the majority were young and in the third or fourth decades of life.

Of these 130 chronic BFP reactors (Table III), ten had systemic lupus erythematosus with LE-cells in the peripheral blood. Seven of them developed manifestations of the disease during observation, months or years after the discovery of the false positive reaction; the other three had the disease when the BFP reaction was first discovered. All ten are women. Four have died of their disease, and post mortem examination of two has confirmed the diagnosis.

TABLE III Principal disorders associated with 130 chronic biological false positive reactions

$\begin{array}{lc}\hline \text { Cause } & \text { No. of cases } \\$\cline { 2 - 2 } \text {$\left.Systemic lupus erythematosus } & 10 \\ \text { Rheumatoid arthritis } & 6 \\ \text { Rheumatic heart disease } & 6 \\ \text { Possible connective tissue disease } & 6 \\ \text { Multiple sclerosis-like neuropathy } & 6 \\ \text { Discoid lupus erythematosus } & 4 \\ \text { Hepatic cirrhosis } & 2 \\ \text { Haemolytic anaemia } & 2 \\ \text { Polyarteritis nodosa } & 2 \\ \text { Hashimoto's thyroiditis } & 2 \\ \text { Sjögren's disease } & 2 \\ \text { Psychotic illness } & 2 \\ \text { Chronic nephritis } & 2 \\ \text { Heroin addiction } & 2 \\ \text { Peripheral vascular disease } & 1 \\ \text { Systemic sclerosis } & 1 \\ \text { Undetermined With symptoms } & 14 \\ & 60\end{array}\right\} \mathbf{7 4}$

Six patients have rheumatoid arthritis and six have had rheumatic heart disease, all with valvular damage.

Six patients have possible connective tissue disease; all are unwell and have a variety of symptoms and physical signs suggestive of connective tissue disorders, as well as abnormal immunological and biochemical findings. It has not been possible to make an exact diagnosis in any of them and LE-cells have not been found in their peripheral blood. It is difficult to predict the possible outcome of the illness in these patients, as many of them have had their symptoms for several years and their condition is very slowly progressive.

Six patients presented with a multiple sclerosis-like neuropathy and on investigation were found to have the biological false positive reaction and evidence of connective tissue disease, probably in the form of SLE.

Discoid LE was found in 4 patients, one of whom had mild haemolytic anaemia.

Hepatic cirrhosis occurred in two patients.

One patient had haemolytic anaemia of the autoimmune type, with a positive Coombs's test and the presence of cold agglutinins.

Two men were found to have polyarteritis nodosa and one of these has since died.

The association of the chronic BFP reaction with other autoimmune diseases is well illustrated by four women, two with Hashimoto's thyroiditis and the two with Sjögren's disease.

Two patients developed well-defined psychotic illness during observation.

Two patients were found to have chronic nephritis.

There were two narcotic addicts in the series and both of them had been injecting themselves with heroin intravenously for a considerable period. It could not be established whether the chronic BFP reaction was related to the use of the narcotics themselves, to additives, or to inadequately sterilized syringes.

One patient had obliterative peripheral vascular disease and died after a long and progressive illness.

Systemic sclerosis was found in one woman, in whom the predominant symptom was dysphagia.

Of the remaining 74 patients, fourteen have symptoms of disease and feel unwell, but no diagnosis has been possible up to the present time. The other sixty are symptom-free, but eight have a persistently raised ESR and moderately severe anaemia. Thus, 52 of the 130 chronic BFP reactors have no clinical or laboratory evidence of disease up to the present time.

The majority, 58, of the chronic BFP reactors (Table IV) were referred by other physicians or surgeons because of the finding of positive results to serological tests. Forty were first found to have the 
reaction when they attended a clinic for venereal diseases, eighteen came from antenatal clinics, and eight from the blood transfusion service. Four were discovered as a result of contact tracing and two because of family investigations.

TAB LE IV Sources of 130 chronic biological false positive reactors

\begin{tabular}{ll}
\hline Source & No. of cases \\
\cline { 1 - 2 } Referred by other physicians & 58 \\
Clinics for venereal diseases & 40 \\
Antenatal clinics & 18 \\
Blood transfusion services & 8 \\
Contact tracing & 4 \\
Family investigation & 2 \\
\hline Total & 130 \\
\hline
\end{tabular}

Hypersensitivity to a variety of drugs had occurred in 26 of the patients, 24 of whom were women (Table V). Six had recurrent attacks of urticaria and four suffered from contact dermatitis. A history of sensitivity to penicillin was obtained in twenty patients, eighteen of whom were women. Six of these had suffered immediate severe reactions to penicillin and in the other fourteen the reaction was delayed. The onset of symptoms of autoimmune disease was related to the administration of penicillin in five patients and this underlines the importance of accurate differential diagnosis between latent syphilis and the BFP reaction before antisyphilitic treatment with penicillin is given to patients with positive STS in the mistaken belief that they have syphilis.

T A B L E V Cases of hypersensitivity to drugs

\begin{tabular}{|c|c|c|}
\hline Total & Hypersensitive to Drugs & 26 \\
\hline & $\begin{array}{l}\text { Sensitive to penicillin } \\
\text { Immediate Reaction } \\
\text { Delayed Reaction }\end{array}$ & $\begin{array}{r}20 \\
6 \\
14\end{array}$ \\
\hline & $\begin{array}{l}\text { Onset of symptoms associated with } \\
\text { penicillin }\end{array}$ & 5 \\
\hline
\end{tabular}

Of the six patients, all youngish women, who presented with symptoms and signs of a neurological disorder resembling multiple sclerosis (Table VI), five had developed a progressive spastic paraplegia 8 months to 3 years before they were found to have the chronic BFP reaction and other evidence of a connective tissue disease. The history and physical examination of all six patients had led to the clinical diagnosis of multiple sclerosis. The discovery of the BFP reaction was a marker which led to more detailed investigations. Some of these patients had noticed minimal joint stiffness and skin lesions during the course of the illness. A moderate elevation of the
TA B LE V I Principal findings in six patients with 'lupoid' neuropathy

1. All young women

2. Symptoms and signs of multiple sclerosis

3. Minimal evidence of involvement of other systems

4. Chronic BFP reaction

5. Elevated ESR

6. Positive tests for antinuclear factor and autoantibodies

7. Raised IgM levels

8. Raised CSF protein

9. Paretic Lange curve

10. LE-cells in the majority

ESR was found in all of them and one had leucopenia. The gamma and alpha-2 globulins were raised and the serum IgM was very high. There were low titres of antinuclear factor and scanty LE-cells were found in the peripheral blood of five of them. Other autoantibodies were also found in all these cases. The cerebrospinal fluids all showed moderate elevation of the protein content and a paretic type of Lange curve.

Very brief reports of two typical cases in the series are as follows:

Case 1, a 35-year-old secretary, has a 5-year history of difficulty in walking. Weakness began in the left foot and leg, and then affected both legs, and urgency of micturition developed. She was diagnosed as having multiple sclerosis. She developed pain and swelling of the fingers, hands, and wrists 3 years later, and 1 year later she had a pleural effusion and recurrent attacks of fever. Walking deteriorated and frequency and urgency of micturition recurred. There were signs of marked spastic paraplegia and tenderness of the small joints of the hands. There was a BFP reaction, an ESR of $32 \mathrm{~mm}$./1st hour, $50 \mathrm{mg}$. of protein and a paretic Lange curve in the CSF, antinuclear factor at a titre of 1 in 40, other autoantibodies and LE-cells in the peripheral blood on two occasions.

Case 2, a 33-year-old housewife, gave a 9-year history of disturbance of walking and of urinary symptoms. Her legs were clumsy and she tended to trip and fall. She had suffered recurrent urticarial skin eruptions and aching in the wrists, feet, and back for 3 years, There was a sudden deterioration in her condition in 1967. She had had two miscarriages, both at 3 months. There was severe spastic paraplegia, tenderness of the metacarpophalangeal joints and proximal interphalangeal joints of both hands and an urticarial rash on the trunk and thighs. In addition to the BFP reaction, the ESR was $50 \mathrm{~mm}$./1st hour, there were antinuclear, antithyroid, and antigastric parietal cell antibodies, and the serum IgM was raised to $332 \mathrm{mg}$. per cent. LE-cells were found in the peripheral blood on two occasions.

These two case histories are typical of the six patients in whom the clinical picture of multiple sclerosis was associated with the BFP reaction and other laboratory findings suggestive of systemic lupus erythematosus. Several of the features of the conditions were unusual for either disease. Nevertheless, there appears to be 
sufficient similarity between the six patients to suggest that they may form a distinct subgroup of the connective tissue diseases, the characteristics of which may be summarized as follows:

The patients are young women, who develop symptoms and signs resembling multiple sclerosis with minimal evidence of involvement of the other systems of the body, associated with the BFP reaction, moderate elevation of the ESR, weakly positive tests for antinuclear factor, other autoantibodies, raised IgM immunoglobulins, moderate elevation of CSF protein levels, a paretic Lange curve and, in the majority, LE-cells in the peripheral blood.

Although involvement of the central nervous system in SLE is well known, there has been no similar description of cases with the characteristics described and it could be that these patients do form a distinct group. For want of a better term, the name 'lupoid neuropathy' has been used to describe the condition, but further study is necessary before the syndrome can be fully understood.

\section{Immunological investigations}

The standard serological tests for syphilis detect antibodies to cardiolipin, which is a 'family' of diphospholipids found mainly on the mitochondrial inner membranes. It is probable, but not fully proven, that Wassermann reagins are autoantibodies produced as a result of the adjuvant effect of treponemes in the body. Autoantibodies found consistently in patients with primary biliary cirrhosis, which react with a lipoprotein component of the mitochondrial inner membrane but not with cardiolipin, have been described by Doniach and Walker (1969) and have been referred to as " $M$ " fluorescence.

Recently it has been possible to study sixty chronic BFP reactors at the Middlesex Hospital in collaboration with the Department of Immunology (Table VII). Of the sixty patients, 58 (96 per cent.) had one or more positive tests for autoantibodies. ' $M$ ' fluorescence, similar to that seen in primary biliary cirrhosis, was found in 34 ( 56 per cent.) at titres varying from 1

T A B LE VII Autoantibodies in sixty patients with chronic BFP reactions

\begin{tabular}{|c|c|c|}
\hline Antibodies & $\begin{array}{l}\text { Positive } \\
\text { Number }\end{array}$ & Per cent. \\
\hline $\begin{array}{l}\text { Mitochondrial fluorescence } \\
\text { CFT rat liver mitochondria } \\
\text { Nuclear fluorescence (ANA) } \\
\text { Smooth muscle } \\
\text { Rheumatoid factor latex FII } \\
\text { Thyroid specific } \\
\text { Gastric parietal cell }\end{array}$ & $\begin{array}{l}34 \\
27 \\
28 \\
16 \\
6 \\
16 \\
6 / 30\end{array}$ & $\begin{array}{l}56 \\
45 \\
47 \\
28 \\
10 \\
27 \\
20\end{array}$ \\
\hline $\begin{array}{l}\text { Total patients with one or } \\
\text { more positive tests }\end{array}$ & 58 & 96 \\
\hline
\end{tabular}

in 5 to 1 in 50 . The autoantibodies were mainly of the IgM class in ten cases, of both IgM and IgG classes in eight, and mainly of the IgG class in three. Non-organ specific complement-fixation reactions were obtained with rat kidney homogenates in 27 cases. Antinuclear antibodies were found in 28 patients ( 47 per cent.), 16 of whom had high titres. The ANA was predominantly of the IgG class and of the so-called "homogeneous' type, similar to that seen in SLE, 'lupoid' hepatitis, and other connective tissue disorders. Smooth muscle fluorescence, which is another antibody marker, was present in sixteen cases $(28$ per cent.). This antibody is uncommon in patients who do not have liver disease. Rheumatoid antiglobulins and thyroid-specific antibodies had an incidence only slightly above that found in normal controls and organ-specific gastric parietal cell fluorescence was present in only six of the thirty patients tested.

The high incidence of tissue antibodies in this series of chronic BFP reactors appears to be related to the high incidence of systemic disease. The mitochondrial fluorescence was usually of low titre and the antibodies were present most frequently in the IgM immunoglobulins. This is in keeping with the findings of other authors that false positive reagin is mostly in the IgM class. The true pathological significance of this association is not understood, but both the cardiolipin antigen and the lipoprotein reactive in ' $M$ ' fluorescence are situated in close proximity on the mitochondrial inner membranes. Both these antibodies are uncommon in the normal population and they are both, therefore, useful markers of a special immunological abnormality related to the connective tissue diseases.

The majority of patients found to have the chronic BFP reaction are healthy. However, in this group of patients, the presence of ' $M$ ' fluorescence usually indicated the development or actual presence of systemic disease. Tests for tissue antibodies and ' $M$ ' fluorescence may be helpful in detecting those patients who are likely to develop connective tissue disease and may, therefore, be important in the follow-up assessment of all patients with the chronic BFP reaction.

\section{Discussion}

There are many difficulties in estimating the incidence of biological false positive reactors among the general population. In Great Britain, at the present time, the majority of patients with syphilis present in the latent stage of the disease, and the commonest cause of positive results to STS is still syphilis, but the incidence of BFP reactions is sufficiently high to warrant careful investigation of all patients with positive serological tests before a diagnosis of latent syphilis is made and antisyphilitic treatment is given. The 
differential diagnosis may be very difficult in certain cases, even with the most modern serological aids. Various studies indicate that the margin of error in diagnosis may vary from 2 to 10 per cent. In addition to the use of specific serological tests and modern immunological techniques, the most important method of achieving accuracy in diagnosis is by prolonged follow-up and surveillance with repeated physical examinations and serological tests. During the 16-year period in which this group of patients was studied, more than twice as many patients had to be eliminated from the series, because it was impossible to persuade them to remain under observation or because there was doubt about the exact diagnosis.

At the present time, despite the great advances made in serological testing for syphilis, the TPI test remains the most reliable method of differentiating between latent syphilis and the BFP reaction, although as a test it is relatively insensitive. The use of the highly sensitive FTA-ABS test adds greatly to the accuracy of diagnosis, but it cannot yet completely replace the TPI test if errors in diagnosis are to be reduced to a minimum. The work of Tuffanelli and others (1967) has helped to establish the limitations of diagnosis based on serological testing alone and has underlined the importance of repeated serological testing over a prolonged period of time. In difficult cases it is essential that more than one TPI test should be performed after an interval of some weeks or months before a definitive diagnosis is made. The modern serological diagnosis of syphilis, although improving continuously, is still imperfect and liable to error, so that the ultimate diagnosis must depend upon assessment of all the factors of the case and the judgment of the physician.

It is extremely difficult to predict the course of the condition in any individual patient after the discovery of the chronic BFP reaction. Long-term observation is essential and this is especially true of women. In many cases, in addition to the clinical progress of the diseases, there is a consistent sequence in the development of abnormal results to laboratory investigations. The chronic BFP phenomenon usually, but not invariably, appears first and is followed by an increase in the ESR. Frequently this situation does not change for many months or years, but in some patients a microcytic, hypochromic anaemia and a leucopenia develop, to be followed by abnormalities of the plasma proteins, especially of the gamma and to a lesser extent of the beta fractions. In some cases, various autoantibodies and antinuclear factors appear at this stage but the exact time at which they develop is as yet unknown. Later still LE-cells may be found. It is not yet known when mitochondrial antibodies of the IgM class first make their appearance in these patients, but their association with systemic disease and their relative infrequency in patients without systemic disease suggests that tests for their presence may prove helpful in distinguishing between those who are likely to develop systemic illnesses and connective tissue disorders in the future and those in whom the condition is likely to remain benign and symptomless.

The exact nature of the immunological abnormality in the chronic BFP reaction is unknown. The evidence suggests that there is a generalized state of immunological hyper-reactivity. This could be interpreted as corresponding to Burnet's concept of antibodyforming clones resulting from somatic mutation, which can then react with any body antigen. There is some evidence that syphilitic reagin arises as the result of a dual response to both treponemal antigen and tissue cardiolipin antigen, whereas in false positive reactions it may be only the tissue antigen which is responsible for antibody production.

The high incidence of sensitivity to drugs and particularly to antibiotics is of great importance. There is abundant evidence that penicillin may be harmful to patients with auto-immune diseases and especially to chronic BFP reactors. In this series the onset of symptoms followed the administration of penicillin in several patients and this association is well known in patients with connective tissue diseases. There is no longer any justification for the common practice of giving a course of penicillin to patients in whom the exact diagnosis is difficult or in doubt, 'just to be on the safe side'. This can do serious harm to the patient by precipitating severe illness and even, in some cases, death.

If evidence of systemic disease is found, or if it develops during observation, the question of prophylactic or symptomatic treatment should be considered. In practice, effective forms of treatment are restricted to corticosteroids and immunosuppressive drugs. Their use is usually limited by the chronic and slowly progressive nature of most of the diseases associated with the chronic BFP reaction. With the corticosteroids the risks involved with prolonged treatment, in which the dose has often gradually to be increased, may be greater than the advantages to the patient. The immunosuppressive drugs have been reported as producing limited success in such autoimmune diseases as acquired haemolytic anaemia and chronic hepatitis. The combination of immunosuppressive agents and corticosteroids has resulted in suppression of the manifestations of SLE and of rheumatoid arthritis. However, the results of this type of treatment have been very variable and experience with it is very limited. The toxic effects of the immunosuppressive drugs are such that they are 
probably indicated in only a few cases with severe and rapidly progressive symptoms. Our experience with any form of therapy is at present too limited for any firm conclusions to be drawn.

The biological false positive reaction is an immunological phenomenon of considerable importance. The acute reaction is precipitated by a number of wellrecognized diseases and immunological procedures and is harmless to the patient, apart from the risk of misdiagnosis. The chronic reaction is associated with a wide variety of systemic diseases and has important prognostic implications for women. It offers an unusual situation in medicine, because it is possible to predict years in advance that a number of the patients with this reaction will later develop serious and occasionally fatal diseases. This fact gives us a special opportunity to study the presymptomatic stages, development, and natural history of the autoimmune diseases, as well as the responsibility for developing safe and effective forms of preventive treatment.

\section{Summary}

The principles and development of the nonspecific and specific serum tests for treponemal disease are reviewed in relation to the recognition of the biological false positive (BFP) phenomenon. 74 cases of the acute BFP are analysed. 130 cases of the chronic BFP are presented to show the high incidence of autoimmune disease and the incidence and variety of autoantibodies. A group of six patients has been identified, all presenting an illness combining features of multiple sclerosis with those of systemic lupus erythematosus, a syndrome not previously described, and termed 'lupoid neuropathy'.

\section{References}

Aно, K. (1968) Brit. F. vener. Dis., 44, 49

Alford, C. A., Jr., Polt, S. S., Cassady, G. E., StraumFJoRd, J. V., and Remington, J. S. (1969) New Engl. $\mathcal{F}$. Med., 280, 1086

Atwood, W. G., Miller, J. L., Stout, G. W., and Norins, L. C. (1968) F. Amer. med. Ass., 203, 549

Bordet, J. (1898) Ann. Inst. Pasteur, 12, 688

- and Gengou, O. (1901) Ibid., 15, 289

CARR, R. D., BeCker, S. W., and CARPENTER, C. M. (1966) Arch. Derm. (Chicago), 93, 393

Collart, P., Borel, L-J., and Durel, P. (1964) Brit. $\mathcal{F}$. vener. Dis., 40, 81

Deacon, W. E., Falcone, V. H., and Harris, A. (1957) Proc. Soc. exp. Biol. (N.Y.), 96, 477

$\longrightarrow$, Freeman, E. M., and Harris, A. (1960) Ibid., 103, 827

- Lucas, J. B., and Price, E. V. (1966) Э. Amer. med. Ass., 198, 624

Delhanty, J. J., and Catterall, R. D. (1969) Lancet, 2, 1099
DoniaCh, D., and WALkeR, J. G. (1969) Ibid., 1, 813

EAgle, H., and Fleischman, R. (1948) f. exp. Med., 87, 369

Harvey, A. M., and Shulman, L. E. (1966) Med. Clin. N. Amer., 50, 1271

HASERICK, J. R., and LoNG, R. (1952) Ann. intern. Med., 37, 559

Hunter, E. F., Deacon, W. E., and Mayer, P. E. (1964) Publ. Hlth Rep. (Wash.), 79, 410

- Norins, L. C., Falcone, V. H., and Stout, G. W. (1968) Bull. Wld Hlth Org., 39, 873

Jokinen, E. J., Lassus, A., and Linder, E. (1969) Ann. clin. Res., 1, 77

KaHN, R. L. (1951) 'An Introduction to Universal Serologic Reaction in Health and Disease'. Commonwealth Fund, New York

-, Marcus, S., McDermott, E. B., and Adler, J. (1942) F. invest. Derm., 5, 459

KIRÁly, K., JoBBÁgY, A., and KovÁTs, L. (1967) Ibid., 48, 98

KraUs, S. J., Haserick, J. R., and Lantz, M. A. (1970) New Engl. F. Med., 282, 1287

Lassus, A. (1969) Int. Arch. Allerg., 36, 515

Laurell, A. B., Oxelius, V. A., and Rorsman, H. (1968) Acta. derm.-venereol. (Stockh.), 48, 268

Mackey, D. M., Price, E. V., KNox, J. M., and Scotti, A. (1969) f. Amer. med. Ass., 207, 1683

Marie, A., and Levaditi, C. (1907) Ann. Inst. Pasteur, 21, 138

MeINICKe, E. (1917) Berl. klin. Wschr., 54, 613

Michaelis, L. (1907) Ibid., 44, 1477

MilleR, J. L., Brodey, M., and Hill, J. H. (1957) $\mathcal{F}$. Amer. med. Ass., 164, 1461

Moore, J. E., and LuTz, W. B. (1955) F. chron. Dis., 1, 297

- and Mohr, C. F. (1952) F. Amer. med. Ass., 150, 467

Nelson, R. A., Jr. (1948) Amer. F. Hyg., 48, 120

- and MAYER, M. M. (1949) F. exp. Med., 89, 369

Pangborn, M. C. (1941) Proc. Soc. exp. Biol. (N.Y.), 48, 484

SAchs, H., Klopstock, A., and WeIL, A. J. (1925) Dtsch. med. Wschr., 51, 589

Scotti, A. T., and Logan, L. (1968) F. Pediat., 73, 242

-, Mackey, D. M., and Trautman, J. R. (1970) Arch. Derm. (Chicago), 101, 328

SequeIra, P. J. L., and WILkinson, A. E. (1955) Brit. $\mathcal{F}$. vener. Dis., 31, 134

Shulman, L. E., and Harvey, A. M. (1964) Amer. $\mathcal{F}$. Med., 36, 174

Tringali, G. R., del Carpio, C., and Giammanco, N. (1966) Riv. Ist. sieroter. ital., 41, 291

- Julian, A. J., and Halbert, W. M. (1969) Brit. $\mathcal{F}$. vener. Dis., 45, 202

Tuffanelli, D. L. (1966) Ibid., 42, 40

- (1968a) Acta derm.-venereol. (Stockh.), 48, 542

- (1968b) Arch. Derm. (Chicago), 98, 606

-, Wuepper, K. D., BradFord, L. L., and Wood, R. M. (1967) New Engl. F. Med., 276, 258

Turner, T. B. (1939) $\mathcal{F}$. exp. Med., 69, 867

WASSERMANN, A., NeIsSer, A., and BruCK, C. (1906) Dtsch. med. Wschr., 32, 745 
WeIL, E., and Braun, H. (1907) Berl. klin. Wschr., 44, 1570

Wilkinson, A. E., and Ferguson, H. G. (1968) Brit. F. vener. Dis., 44, 291

and RAYNER, C. F. A. (1966) Ibid., 42, 8

Yobs, A. R., Clark, J. W., Jr., Mothershed, S. E., Bullard, J. C., and ARTLEy, C. W. (1968) Ibid., 44, 116

Zellman, H. E. (1954) Amer. F. Syph., 38, 506

Maladies de système et réaction biologiquement faussement positive SOMMAIRE

On passe en revue les principes et les applications des tests sériques pour les tréponématoses, non spécifiques et spécifiques, en relation avec l'identification du phénomène de la fausse positivité biologique (BFP). 74 cas de BFP 'aigus' sont analysés. 130 cas de BFP chroniques sont présentés qui illustrent l'incidence élevée des maladies auto-immunitaires ainsi que la fréquence et la variété des auto-anticorps. Un groupe de 6 malades a été isolé qui, tous, présentaient un état morbide associant des manifestations de sclérose en plaques à celles du lupus érythémateux 'systémique'; cette association constitue un syndrome non décrit jusqu'ici et auquel on a donné le nom de neuropathie lupoïde. 